\title{
LA PUESTA EN ESCENA DE LA FAMILIA INMIGRANTE PUERTORRIQUEÑA
}

\author{
POR
}

\author{
ALBERTO SANDOVAL SÁNCHEZ \\ Mount Holyoke College,
}

Una tarde parti hacia extraña nación pues lo quiso el destino ...

"En mi viejo San Juan" (1943) de Noel Estrada

Mientras pensaba este trabajo sobre la re-presentación de la familia inmigrante en el teatro puertorriqueño, me encontré tarareando dos canciones anglo-americanas: "America" de West Side Story y "America" de Neil Diamond. ${ }^{1}$ Dado que ambas canciones exaltan el mito de la inmigración a los Estados Unidos como la tierra de la libertad y de la oportunidad, ambas, como es sabido, funcionan para la propagación ideológica del "American Way of Life" y del "American Dream". En esta articulación discursiva del poder estadounidense, estas canciones activan modos de re-presentación y de identificación para con el sujeto político anglo-americano. Una vez que se escuchan las canciones, (acompañadas por el tarareo del sujeto), un sistema de valores, creencias, sentimientos, formas de ser y de hacer se re-activan dando al oyente una toma de posición en "modelos de y para" la acción socio-política. ${ }^{2}$ Dichos modelos culturales dominantes convalidan y justifican una construcción social de la realidad en los Estados Unidos y su grandeza como nación imperial. Sin embargo, cuando se aplica el paradigma del mito de éxito a los puertorriqueños inmigrantes, es decir, el paradigma de movilidad social y de trabajos permanentes en "la tierra prometida de la oportunidad", uno confronta un relato diferente, el

Una versión en inglés de este trabajo fue leída en el Simposio Interdisciplinario "Literature and Family: Family Forces of Change" en Marquette University, Wisconsin, en abril de 1988. Quisiera expresar mi gratitud al Comité Organizador por su apoyo, en especial a Raquel Aguilú de Murphy. También aprecio la ayuda de Efraín Barradas por material bibliográfico mientras preparaba este trabajo.

${ }^{1}$ Vease la cancion "America” en West Side Story (New York: Dell Publishing Corporation, 1965) 167-169. La letra y la música de "America" de Neil Diamond son publicadas por Hal Leonard Publishing Corporation.

${ }^{2}$ Los términos "modelo de y modelo para" provienen de Clifford Geertz. Véase The Interpretation of Cultures (U.S.A.: Basic Books, 1973) 93-94. 
cual aparece históricamente condicionado. ${ }^{3}$ Por esta razón, debemos desplazarnos fuera del discurso de articulación del poder dominante para comprender mejor sus modos de representar la otredad marginal. Por otra parte, conviene nos conviene ubicarnos en la periferia para distinguir y leer el discurso no-oficial sobre la re-presentación histórica de la inmigración puertorriqueña ejercida por los puertorriqueños mismos. En estos términos, los versos de tales canciones:

I like to be in America!... /Everything free in America" y "On the boats and on the planes/ they are coming to America/Never looking back again, ... /Got a dream they've come to share .... .4

se re-velan comoideologemas oficiales hegemónico-imperiales que excluyen las experiencias históricas del diario vivir de los puertorriqueños que en el siglo XX han inmigrado en su mayoría a la Ciudad de Nueva York. ${ }^{5}$ En este trabajo estudiaré cómo el teatro puertorriqueño de 1938 hasta la década de los ochenta pone en escena las crisis, discontinuidades y contradicciones producidas por la inmigración. Este teatro hila una narrativa que es sobre todo sincrónica antes que teleológicamente diacrónica. Es decir, estas obras dramáticas construyen un texto multi-cultural que es el producto y la producción de desplazamientos, desarticulaciones y desmembramientos de valores culturales, instituciones socio-políticas y nociones del yo (sujeto). Estas obras proclaman la lucha de los inmigrantes por mantener su realidad socio-cultural y por adaptarse al ambiente anglo-americano. Sin embargo, en estas obras dramáticas no se da simplemente una lucha de un solo individuo con el medio ambiente sino la lucha de la institución de la familia y de sus miembros como un todo. En las obras que analizaré: Esta noche juega el jóker, La carreta, Encrucijada, Pipo Subway no sabe reir, Short Eyes, Simpson Street y Migrants, ${ }^{6}$ la institución de la famila

${ }^{3}$ El gran relato mítico del éxito anglo-americano se centra en la movilidad social. El teatro y el cine son los medios más importantes que representan el ascenso social, en particular los musicales de Broadway, en los cuales una persona pobre y desconocida llega a la Ciudad de Nueva York y al final se convierte en super-estrella. De este modo, el "American Dream" del "making it" se mitifica y perpetúa en los desenlaces felices de la comedia musical.

* Véase la nota 1.

${ }^{5}$ Frederick Jameson en The Political Unconscious. Narrative as a Socially Symbolic Act (New York: Cornell University Press, 1981) define el "ideologema" de la siguiente manera:

The ideologeme is an amphibious formation, whose essential structural characteristic may be described as its possibility to manifest itself either as a pseudoidea - a conceptual or belief system, an abstract value, an opinion or prejudice- or as a protonarra tive, a kind of ultimate class fantasy about the 'collective characters' which are the classes in opposition" (87).

${ }^{6}$ Fernando Sierra Berdecía, Esta noche juega el joker. España: Manuel Pareja, 1962. La obra se publicó originalmente en 1939; René Marqués, La carreta. Puerto Rico: Ediciones Cultura, 1969. La carreta se publicó originalmente enAsomante 4 (oct-dic.,1951) 67-87 yenAsomante 1 (enero-marzo,1952) 54-78; Manuel Méndez Ballester, Encrucijada (San 
puertorriqueña se desvía, se descentra, se modifica y se transforma una vez que se ubica en los Estados Unidos en la encrucijada del aquí y del allá, del presente y del pasado, de lo rural y de lo urbano, de la etnicidad y de la asimilación, de la diferencia y de la semejanza. El verdadero protagonista/sujeto de estas obras, la familia, deviene una institución en proceso de cambio y tiene que "bregar" con su definición, sus nuevas formaciones y reconstrucciones que le exige el espacio anglo-americano. Sobre todo demostraré, en las páginas siguientes, cómo la familia puertorriqueña, después de la inmigración, es un cuerpo político dinámico de polarizaciones internalizadas y contradicciones, rupturas $\mathrm{y}$ divisiones, oscilaciones y dislocaciones, discontinuidades y continuidades, de las que debe surgir un nuevo sujeto, una "subjetividad" bilingüe/bicultural y una nueva definición de lo que habrá de ser la hispanidad y la comunidad latina en los EE.UU.

Si la literatura, específicamente el teatro, es instrumental en la mediación de discursos socio-ideológicos en lo que concierne a la producción imaginaria del sujeto, de las instituciones sociales y de la política, la literatura puertorriqueña ha registrado la situación histórica y las experiencias de la inmigración masiva de casi tres millones de puertorriqueños a los EE.UU. ${ }^{7}$ Partiendo de estas circunstancias, las novelas puertorriqueñas y el teatro re-presentan y participan en el proceso socio-histórico de una nación colonizada que ha tenido que emigrar por factores demográficos y socio-económicos, tales como mejores oportunidades y condiciones de empleo, prosperidad, comfort y mejores salarios. ${ }^{8}$ Por ende, desde el espacio literario se da testimonio de la clase inmigrante trabajadora y pobre que se desbordó hacia los EE.UU. en pos de oportunidad de empleo y

Juan: 1958); Miguel Piñero, Short Eyes. U.S.A.: Hill and Wang, 1984. Short Eyes fue presentada en Broadway en 1974; Jaime Carrero. Pipo Subway no sabereir. Puerto Rico: Ediciones Puerto, 1973; Edward Gallardo, Simpson Street (New York: 1975); quisiera agradecerle a Carlos A. Rodríguez Matos el haberme enviado el manuscrito de la obra. En lo que concierne a Migrants, tuve la oportunidad de asistir a la representación teatral por Teatro Pregones en la Universidad de Massachusetts, Amherst, en octubre de 1987.

${ }^{7}$ Según Economic Notes 9 (Labor Research Association, Inc.,septiembre, 1979) en un número sobre Puerto Rico: "[ $\mathrm{t}$ ]oday, more than 2.4 million Puerto Ricans reside in the United States with an estimated 3.3 million still living in their homeland", (1); Tambien véase "Migration of Puerto Ricans" en la página 5. Recomiendo Labor Migration Under Capitalism: The Puerto Rican Experience (New York: Monthly Review Press, 1979), en particular el capitulo 5 "Migration and Industrialization, 1930 to the Present" para un excelente análisis de la migración puertorriqueña a los EE.UU.

- Para un estudio del tema de la emigración en las novelas puertorriqueñas, véase Rafael Falcón, La emigración a Nueva York en la novela puertorriqueña (España: Albatros Ediciones Hispanofila, 1983). Para testimonios sobre la experiencia de la migracion por escritores puertorriqueños en los EE.UU. véanse Pedro Juan Soto, "The City and I" en Literature and The Urban Experience, editado por Michael C. Jaye y Ann Chalmers Watts (New Jersey: Rutgers University Press, 1981) 185-191; y Nicholasa Mohr "Los puertorriqueños en Nueva York: evolución cultural e identidad" en Imágenes e identidades: el puertorriqueño en la literatura, editado por Asela Rodriguez de Laguna (Puerto Rico: 
prosperidad. Mas por contradicción, después de la llegada a las ciudades industrializadas, los puertorriqueños fueron segregados por su origen, raza y clase. Como resultado emergió la subordinación, la opresión, la indigencia económica y la marginación de una minoría inmigrante poco dispuesta a asimilarse instantáneamente. En su búsqueda por un mejor bienestar dentro del imperio capitalista, el pueblo puertorriqueño quedó atrapado y arrinconado al margen del "American Dream".

Dado que los puertorriqueños no son necesariamente exiliados políticos, pueden ir y venir de la isla sin problemas, por lo que siempre la han visitado hasta por largas estadías debido su proximidad. Contrariamente a ciertos exiliados políticos privilegiados, los puertorriqueños nunca han sido glorificados por el discurso dominante del poder; por el contrario, han sido constantemente estereotipados de forma negativa. Así se les ve en West Side Story donde los puertorriqueños aparecen en pandillas criminales destructivas que amenazan el modo de vida anglo-americano. Tampocoel exilio-económico del puertorriqueño ha sido exaltado por ser la primera "inmigración aérea" a los EE.UU., una inmigración no de individuos sino de familias completas. ${ }^{9}$

No hay duda de que la historia mítica del éxito anglo-americano se concentra en un solo individuo, el self-made man que lucha por alcanzar una meta, como el ratón en la película animada de Stephen Spielberg, An American Tail. ${ }^{10} \mathrm{Si}$ el ratón en la película se separa de su familia y persevera hasta

Huracán, 1985) 185-189. También recomiendo Memorias de Bernardo Vega, edición de César Andreu Iglesias (Puerto Rico: Huracán, 1988) para el testimonio, después de su migración en 1916, de su propia experiencia migratoria, y para la historia de la comunidad latina proletaria en la Ciudad de Nueva York.

"Nicholasa Mohr en la "Introducción" a El Bronx Remembered (Houston: Arte Público Press, 1986, IX) declara sobre la inmigración puertorriqueña y cómo ésta fue favorecida por la transportación aérea:

There have been Puerto Ricans living in the mainland U.S.A. since the middle of the last century. But it was after the second World War, when traveling became cheaper and easier, that the greatest influx began. In 1946, Puerto Ricans could purchase, for a small amount of money, a one way ticket to the mainland. As citizens they did not face immigration laws or quotas ... and so they arrived by the tens of thousands, first by freighters and later by airplane".

Es necesario señalar que esa "inmigración aérea" fue registrada por Pedro Juan Soto en su "Prólogo" al libro de cuentos Spiks (Puerto Rico: Editorial Cultural, 1973): "... todos los personajes bien pueden haber viajado en el mismo avion de la protagonista del primer cuento ..." (10). En este contexto es importante considerar que :

the massive migration of Puerto Ricans to the mainland began with the government's effort to industrialize the island during the late 1940's. Development schemes included encouragement to leave; migration was seen as both a social safety valve and an economic asset. Encouraged also by the availability to cheap air fares due to the surplus of airplanes after World War II (Puerto Ricans are the first airborne migrants in history), the Puerto Rican population on the mainland quadrupled between 1940 and 1950, and tripled again by 1960". Xavier F. Totti, "The Making of a Latino Ethnic Identity", en Dissent (otoño de 1987), 538.

${ }^{10}$ An American Tail (Universal City Studios, 1986). En el resumen en la cubierta del video se exalta el viaje migratorio de Rusia a América del ratón: "Meet Fievel. In his search to find his family, he discovered America". 
reunirse nuevamente, los puertorriqueños, por otra parte, se mantienen unidos desde el principio hasta el final - "All in the family"/Todos en familia" conviven en diminutos apartamentos. La percepción del anglo-americano de dicha mudanza colectiva queda inscrita en la línea de West Side Story: "They keep coming like cockroaches". ${ }^{11}$ Generalmente es un joven soltero que llega solo a la ciudad y se ve obligado a con-vivir en un congestionado apartamento. Luego trae a sus padres y parientes, y hasta amigos se han de quedar con ellos. De este modo, lo que se establece es un circuito migratorio de los miembros de la familia y de núcleos de parentesco (Spanish Harlem, El Barrio, El Bronx, Los Sures). ${ }^{12}$ Más allá de esta épica histórica y en lo que a la literatura se refiere, las obras dramáticas presentan una cadena migratoria de núcleos de familia de la zona rural de la Isla a los arrabales de San Juan, y de allí a la metrópoli imperial, la Ciudad de Nueva York. Una vez des-plazado hacia los EE.UU. el inmigrante es colocado en un proceso de inmigración interna al tener que ir en busca de empleo a otras ciudades industriales como Filadelfia y Chicago, o a las áreas agrícolas de California.

La carreta de René Marqués es la obra que mejor dramatiza la diáspora de la familia puertorriqueña de una economía rural en quiebra en su inicial movilidad hacia al ghetto de San Juan, "La Perla", y en su posterior traslado a la ciudad de Nueva York como proletariado inmigrante. ${ }^{13}$ Esta obra constituye

11 West Side Story (Beta Productions, 1961). West Side Story se puso en escena en Broadway en el teatro Winter Garden, Ciudad de Nueva York, en 1957.

${ }^{12}$ Nicholasa Mohr resume la llegada de los puertorriqueños a la Ciudad de Nueva York y la formación de la comunidad latina de la siguiente manera:

A small percentage went to work as migrant workers in the rural areas of the country. The majority settled in New York City. Many went to live in Spanish Harlem, known as El Barrio, an older community of Spanish-speaking people, on Manhattan's Upper East Side. There they joined family and friends. Others moved into congested neighborhoods inhabited by the children of earlier immigrantgroups. Thus, they formed new neighborhoods in Brooklyn and Manhattan's Lower East Side. One area in particular was heavily populated by these newcomers, and became an extension or suburb of Spanish Harlem. This was the South Bronx, known to the Puerto Ricans as "El Bronx". (El Bronx Remembered, ix.)

También véanse Memorias de Bernardo Vega y "Spanish Harlem" en The WPA Guide to New York City (New York: Random House, 1982) 265-268. publicado originalmente en 1939

${ }^{13}$ Oscar Lewis en La Vida, A Puerto Rican Family in the Culture of Poverty - San Juan and New York (New York: Random House, 1965) estudia desde una perspectiva antropológica-etnográfica la cultura de la pobreza puertorriqueña y el proceso de inmigración. Lewis establece, tal como ocurre en La carreta, los tres pasos migratorios: "The majority of migrants in the New York sample has made a three-step migration from a rural birthplace in Puerto Rico to a San Juan slum to New York" (XXXVIII). Lewis examina tanto los cambios y la crisis de la familia como la lucha por la sobrevivencia. Sin embargo, el lector contemporáneo debe de construir los estereotipos de la cultura de la pobreza puertorriqueña que este estudio antropológico puso en circulación en la década del sesenta, y los que en cierta manera corroboraron los estereotipos negativos de West Side Story. 
la experiencia y el ciclo migratorio de la familia puertorriqueña. No sólo revela sus vicisitudes tanto en el ambiente rural como en el urbano sino que también proyecta las alteraciones y rupturas que afectan el hogar hispano como resultado de la crisis socio-económica. Si en la zona rural la familia se mantenía dentro de una unidad de seguridad, apoyo, autoridad, afecto, fortaleza y continuidad de valores y tradiciones, en el espacio urbano todo ello es desmantelado y alterado. Los miembros de la familia comienzan así a confrontar cambios e incoherencias; la noción del "yo" y los roles (padre, madre, deberes de los hijos) son desarticulados y desintegrados. Como resultado, el drama trae a escena la cáda de los valores de la institución de la familia, junto a la crisis del patriarcado. ${ }^{14}$ Por estas razones:

1) se propone al matriarcado en su capacidad de recuperar las pasadas jerarquías y las relaciones e interacciones del poder y de géneros;

2) el desempleo y la pobreza tienden a enajenar a los individuos de la familia;

3) la drogadicción, criminalidad, delincuencia, locura y la prostitución desplazan y re-emplazan la noción de respeto y obediencia hacia los previos valores del orden rural y de las obligaciones familiares;

4) en lo religioso, la sacralidad de la sociedad católica es desmantelada y sustituida por un nuevo modelo secularizado de la sociedad capitalista y de ética protestante del trabajo. ${ }^{15}$

En La carreta, como en las otras obras seleccionadas para este trabajo, queda representado el proceso de resquebrajamiento de las tradiciones, la confusión de los cambios institucionales y la confrontación cultural entre lo

14 Adrienne Rich define el patriarcado de la siguiente manera:

Patriarchy is the power of the fathers: a familial-social, ideological, political system in which men, by force, direct pleasure, or through ritual, tradition, law, and language, customs, etiquette, education, and the division of labor, determine what part women shall or shall not play, and in which the female is everywhere subsumed under the male. It does not necessarily imply that no woman has power, or that all women in a given culture may not have certain powers. Of Women Born (New York: W. W. Norton, 1986) 57.

${ }^{15}$ Lawrence Stone define la ética protestante de la siguiente manera:

The Capitalist/Protestant ethic is one of self improvement, independence, thrift, hard work, chastity and sobriety, competition, equality of opportunity, and the association of poverty with moral weakeness". The Crisis of Aristocracy (London: Oxford University Press, 1967) 6.

Para un estudio sobre el proceso de asimilación de los grupos étnicos en los EE.UU. y su adhesión a la ética protestante durante su aculturación, véase "The Role of the Family in Acculturation and Assimilation in America: A Psychocultural Dimension" de Jackeline S.Mithun, en Cultura, Ethnicity and Identity, editado por William C. McCready (Chicago: University of Chicago, 198) 209-221. Mithun declara sobre la "etica protestante":

As the primary molder of culture, the family conditions attitudes, beliefs, and values toward education, work, authority, personal relations and time orientations. WASP families, generally speaking, foster the 'Protestant ethic' whose major tenets are industriousness, agressivity, competition, speed, perseverance, goal oriented behavior, future-time orientation, literacy, cleanliness, repression as sexuality, innovation, and self reliance as expressed in a striving for self-sufficiency and individualism (214). 
hispano y lo anglo-americano, el choque entre la familia hispánica extendida y la familia nuclear de clase media anglo-americana. ${ }^{16}$ De modo que los dramas relacionados con la inmigración constituyen una narrativa en la que se articula el giro de lo rural al espacio urbano, y en la que se muestra cómo estas familias resultan víctimas de la crisis económica y el desempleo, y cómo estos cambios tan traumáticos alteran la unidad familiar. De acuerdo al sociólogo David T. Ábalos, tal radical proceso de desmembramiento, desintegración y erosión de la tradición comienza con:

... the shift from the rural to the urban centers with all of the demands of a market society. That market society meant that we could no longer share common values that held the previous traditional peasant society together. Adjusting to the urban centers and to U.S. society really meant choosing a new god, with a new vision of life. Often it meant a secularization but in reality it meant the presence of a new sacred source because the city did not recognize the old gods. The new way of life, the new paradigm and its god is the god of incoherence with a new corresponding experience of fragmentation. The breaking and dying of our traditional way of life led many of our relatives, and indeed led us, to choose the pursuit of power as our god. ${ }^{17}$

La cita anterior verbaliza las posturas filosóficas y políticas que confrontan las familias latinas en los EE.UU. No hay duda de que la religión católica del inmigrante es retada por la ética protestante; aún más, el antiguo Dios católico, como también el culto a la Virgen María y a los santos, son reemplazados por el nuevo dios del poder y de la competencia capitalista que aparece inscrito en el billete norteamericano: IN GOD WE TRUST

A continuación prestaré particular atención a cómo la institución de la familia migrante se instala en la encrucijada de una doble formación estructural que lucha por definirse, reconstruirse y re-formularse según cruza y yuxtapone fronteras socio-políticas y culturales. Dentro de este contexto los miembros de

${ }^{16}$ Betty Garcia-Bahme en "La Chicana and the Chicano Family" da las siguientes definiciones para "familia nuclear" $y$ "familia extendida":

1. Nuclear family - most common, consisting of parents and dependent children, living apart from relatives, also called a conjugal family, because the social unit around which it develops is typically, but not always, a married couple;

2. Extended family - comprised of a network of relatives that radiates from a particular nuclear family.

En Essays on La Mujer, editado por Rosaura Sánchez y Rosa Martínez Cruz (University ofCalifornia: Chicano Studies Center, 1977). Recomiendo este trabajo para el entendimiento de la familia latina y el rol de las latinas en los EE.UU. según cambian las estructuras y las funciones de la familia. También véanse: The Women in the Family en La Chicana, the Mexican American Woman de Alfredo Mirandé y Evangelina Enriquez (Chicago: The Universitiy of Chicago Press, 1979) y Families and Work, editado por Naomi Gerstel y Harriet Engel Gross (Philadelphia: Temple University Press, 1987).

17 "The Politics of the Latino Family", Journal of Hispanic Policy, publicado en Harvard University, vol. 2 (1986-1987) 70. 
la familia experimentan un proceso histórico de cambio marcado por el doblez, el "ni esto ni lo otro", las divisiones, contradicciones y diferencias según esta familia se enfrenta a la sobrevivencia, los modos de resistencia y ajustes en el espacio foráneo, hostil y etnocéntrico.

Tanto La carreta comola Encrucijada, de Manuel Méndez Ballester, trazan el peregrinaje del puertorriqueño hacia la ciudad. Aunque Encrucijada se desarrolla en el ghetto urbano, Spanish Harlem, el viaje de la familia desde el área rural a San Juan y de ahí a la Ciudad de Nueva York, como vimos, ya había sidoreconocidoen los primeros dos actos de La carreta cuando se traza la historia de una familia proto-típica de inmigrantes puertorriqueños. En ambas obras es la familia quien es amenazada por la movilidad, el desplazamiento, la hostilidad y los nuevos modos de actuar. Las hijas, en estos dramas, se hacen prostitutas para sostener económicamente a la familia. Los hijos son encarcelados Chaguito por robo y Mario por su militancia política. El empleo obtenido por los hijos no lleva al éxito sino al fracaso y a la vergüenza. La madre es una mujer fuerte, un ser activo que procura preservar el orden y las jerarquías de poder, y quien ejerce las decisiones importantes concernientes al futuro de la familia. Por ejemplo, dice la madre en La carreta: "Mientrah yo viva mi familia será mi familia. Una familia con digniá y vergüenza" (63-64). Pero no puede darle sostén a estas palabras según la familia se le desintegra y según su papel de matriarca llega a su final. Por lo que se refiere a Encrucijada es el hijo quien se lamenta de tal desarticulación. En esa obra, Felipe dice: "Me parece que de un momento a otro se nos desmorona la familia" (101).

Aunque la madre es la que traza, preserva y apoya la cultura, su labor se torna más difícil cuando también el patriarcado se desintegra luego de la migración. ${ }^{18}$ En La carreta, el abuelo permanece en la Isla y luego muere, señalándose así la muerte del patriarca. En las otras obras, los hijos son encarcelados; los maridos, avergonzados por el fracaso y por no haber podido sostener la familia, abandonan a sus esposas. Un personaje femenino de $L a$ carreta resume el sentimiento de desesperación, soledad y ansiedad en un relato sobre sus varios maridos en el exilio, el primero de los cuales se suicida mientras que el otro acude a las drogas para sobrevivir:

Mi primer mario, el que traje de Puerto Rico, era tan honrao, tan honrao, que porque estuvo un mes sin encontrar trabajo no lo pudo aguantar y se tiró de la azotea. Tenía demasiada vergüensa. Pero me dejó en la calle con una hija pa mantener. Este en cambio tiene tan poca, tan poca vergüensa, que no sabe ser honrao. Y me está volviendo loca (142).

\footnotetext{
${ }^{18}$ Sheila Radford-Hill en "Considering Feminism as a Model for Social Change" declara sobre la toma de posición de poder de las mujeres negras:

The role of black women as culture makers and culture bearers was nothing less than a major struggle for culture against extinction. Our culture of resistance has ensured the survival of our race and our community. En Feminist Studies: Critical Studies editado por Teresa de Lauretis (Bloomington: Indiana University Press, 1986) 168.
} 
Dado que los personajes varones des-aparecen en La carreta al final del drama (luego de la muerte del hijo), tanto la madre comola hija deciden regresar a la Isla. Es aqui donde el patriarcado y el matriarcado llegan a un paro. ${ }^{19} \mathrm{En}$ lo que se refiere a la figura patriarcal en Encrucijada, las figuras del padre y del abuelo resultan en entidades débiles des-poseŕdas de autoridad y poder. ${ }^{20}$ Los dos hijos se burlan del pasado del padre, articulándose así la caída del poder, la imagen y el discurso del patriarca hispano. Tal mofa es consecuencia de la desintegración de las jerarquías familiares y de las relaciones de respeto. Por ello, hacia finales del drama, el nieto jugando al vaquero le dispara a su abuelo. He aquí obviamente un acto simbólico en significación tanto del deseo de desaparición del patriarca abuelo como de su posición de autoridad. El niño le grita: “Tienes que caer muerto! ¿Que te caigas, abuelo!” (142). El abuelo es así silenciado, eliminado y castrado por un nuevo cuerpo de valores, en una nueva articulación discursiva de poder, - -la del "Cowboy".

La desintegración del patriarcado es también asunto de vital importancia en el primer drama que trata de la inmigración puertorriqueña a la Ciudad de Nueva York. Se trata de Esta Noche juega el jóker de Fernando Sierra Berdecía. En esta obra una pareja invierte sus roles matrimoniales. ${ }^{21}$ La esposa es el

${ }^{19}$ A causa de las actitudes chauvinistas de René Marqués, el matriarcado debe ser cuestionado en sus obras. ¿Hasta qué punto la madre en La carreta está moldeada por una ideología misógina? Efrain Barradas ha observado cómo Marqués atribuyó el poder matriarcal a la dominación norteamericana de la Isla: Aquí [El puertorriqueño dócil] el autor defiende ... el machismo tradicionalista como arma contra el supuesto matriarcado que nos va dominando y que es el producto, según Marqués, de la dominación estadounidense. Esta pugna entre el mundo machista tradicional y el cambio, que Marqués insiste en identificar con un supuesto matriarcado, es otra muestra de nuestra 'docilidad' colectiva. "El machismo existencialista de René Marqués", Sin Nombre 3 (oct.dic., 1977) 76.

${ }^{20}$ David T. Abalos declara sobre la crisis del patriarcado lo siguiente:

The children also saw the change in the patterns, the loss of authority and respect. This breaking often led to their rejection of old relationships. The father who was conscious of his loss of power and respect frequently turned to violence to reassert control. If the father became impossible the mother could now evict him from the home; women now experienced some domination over men. In many cases, traditional roles were reversed". "The Politics of the Latino Family", 73.

Actualmente Juan Gelpí tiene en preparación un libro crítico sobre el discurso patriarcal puertorriqueño en las décadas del treinta al cincuenta, y su desintegración en los sesenta. $\mathrm{Su}$ acercamiento e interpretación bien pueden aplicarse a la crisis del patriarcado en $L a$ carreta y Encrucijada. Gelpi declara sobre Marqués: "In fact, in Marqués works we see the highest point of this discourse, but The Docile Puerto Rican represents the moment when patriarchal discourse begins to weaken in Puerto Rico". La cita proviene de un trabajo leído en Smith College, Northampton, "Recent Puerto Rican Fiction", el 30 de marzo de 1988.

${ }^{21}$ No estoy de acuerdo con que el género determine las acciones sociales y los roles de los personajes en la obra. Es importante señalar que el dramaturgo tiene un punto de vista chauvinista al invertir las acciones sociales y económicas del hombre y de la mujer. Por tal inversión los personajes masculinos se ríen del marido "castrado" quien ha sido desposerdo de su rol tradicional de "macho". 
sostén de la casa y ocupa la posición de poder: "Jefe de un departamento de exportación en una casa manufacturera [de navajas de seguridad]" (43) mientras que el esposo sólo ha logrado trabajos de tipo manual en hoteles y restaurantes. El esposo cocina y ejerce otras faenas del hogar mientras que su esposa sale a divertirse con sus amigos. Un personaje masculino riéndose, y advirtiendo sobre la subordinada situación de Arturo, dice: "Aquí vas a ver otra de esas cosas que en Nueva York te parecen vueltas de revés" (30); "Aquí María jamás pisa la cocina ... y tiene un amigo que en la propia casa parece el marido" (42-43). No sólo demuestra el drama la inversión de los roles de los géneros socio-económicos (como la capacidad de la esposa de castrar a su marido mediante su simbólica posición como distribuidora de navajas de afeitar), sino que también evidencia la inmigración del hombre solitarioen búsqueda de empleo, amistad, o dispuesto al casamiento inmediato. Aún más, la desesperación y fracaso del hombre es relatada por uno de los personajes femeninos cuyo esposo la ha abandonado: "Nos casamos en Filadelfía. Después, él quedó sin trabajo, vino a Nueva York, y de aquí pasó a Chicago. Yo vine a Nueva York más tarde". "Me daba vergüenza decir que mi marido me había abandonado" (94). "Perdió el empleo y se me fue una noche" $(90)$. Tales declaraciones acentúan además, cómo los personajes masculinos se desplazan por los EE.UU. en búsqueda de mejores oportunidades de empleo. $\mathrm{O}$ bien abandonan a sus familias, o llevan consigo a sus esposas e hijos. Por lo que se refiere a Esta noche juega el jóker, los personajes Julio e Isabel se trasladan a Filadelfia. En Encrucijada Chana y su esposo angloamericano (el conserje del edificio) se mudan a San Antonio en Tejas; Mario, Lorna (angloamericana ésta) y Tony se van a Miami. Estos matrimonios son también inter-raciales marcándose así una nueva generación de puertorriqueños y, lo que a la misma vez señala, especialmente mediante Tony, el nieto, la condición bilingüe y bicultural de la nueva familia emigrante. ${ }^{22}$ En su partida, el brindis de Chana por la familia puede ser considerado como la proclamación de la familia en su rol del verdadero protagonista de estas obras dramáticas. No es el individuo sino la familia quien debe sobrevivir como institución: "Brindo por ustedes dos y por sus hijos. Que la familia se conserve en salud y uníos como Dios manda" (149). El futuro de la familia migrante puertorriqueña aparece ahora anclado en los EE.UU., dispuestos a establecerse y a luchar por su sobrevivencia en ese espacio. No se trata de regresar a la Isla, como en el final de La carreta, sino más bien es su anticipación de la nueva actitud que nos revelará Tato Laviera en su libro de poesía titulado La carreta Made a U-turn $(1975){ }^{23}$

22 Chana dice sobre la condición bilingüe y bicultural de Tony: “QQué cacho e nieto tiene usted, don Alfonso! Mitad yanqui y mitad boricua" (148).

${ }^{23}$ La carreta Made a U-Turn (Houston: Arte Publico Press 1981). Recomiendo como lectura complementaria al texto poético el estudio de Juan Flores, John Attinaso y Pedro Pedraza, Jr., "La carreta Made a U-Turn: Puerto Rican Language and Culture in the United States"; Daedalus 110 (primavera, 1981) 193-217. 
La segunda parte de La carreta no había de ser escrita hasta que los puertorriqueños nacidos en los EE.UU., los nuyorican, se enfrentaran al mito del eterno retorno y a la nostalgia reaccionaria. ${ }^{24}$ Éstos habían de situarse en el eje de realidades históricas y de una conciencia cultural de sujeto latino bilingüe. Así lo expresa poéticamente Sandra María Esteves:

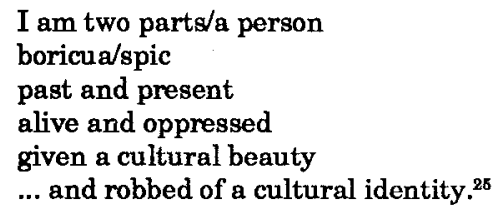

Es evidente que para los poetas de los años sesenta hubo una conciencia política que condenaba la opresión, la discriminación y la marginación. ${ }^{26}$ En lo que concierne al teatro latino, las décadas del sesenta y del setenta se caracterizaron por una conciencia colectiva de la condición de pobreza, de los dilemas de choques culturales, y de la problemática resultante de la catástrofe de la experiencia migratoria. Las producciones teatrales se centraban en las condiciones sociales, las situaciones del diario vivir del marginado y del lumpen. En este periodo la crisis de identidad y la desintegración de la familia ya constituía un proceso demasiado dinámico y conflictivo para poder culminar mitificándose en un desenlace feliz. Veamos.

\footnotetext{
${ }^{24}$ Según Miguel Algarín en su prólogo "Introduction: Nuyorican Language" en Nuyorican Poetry: An Anthology to Puerto Rican Words and Feelings, ed. por Miguel Algarín y Miguel Piñero (New York: William and Morrow, 1975), "Nuyorican" es un concepto que se basa en el lenguaje y en la experiencia:

The experience of Puerto Ricans on the streets of New York has caused a new language to grow: Nuyorican. Nuyoricans are a special experience in the immigration history of the city of New York (15);

The Nuyorican will have to continue to express himself without 'legitimate rules' to govern his speech. We have to admit that speech comes first. We first verbalize the stresses of street experience and then later, in the aftermath of our street survival, we will sit and talk our newness and how to shape it (19).

Sandra Maria Esteves ha resumido el significado del concepto en los siguientes términos: Cuando se discute el término Nuyorican o cualquiera de sus variaciones Neorican, New Rican o Nuevayorquino Puertorriqueño, simplemente a lo que refiere es a la experiencia puertorriqueña tal como se proyecta en Estados Unidos. ("Ambivalencia o activismo desde la perspectiva poética de los Nuyoricans") en Imágenes e identidades, 195.

También, para un análisis del concepto "Nuyorican", véase la introducción de Herejes y Mitificadores, antología editada por Efraín Barradas y Rafael Rodríguez (Puerto Rico: Huracán, 1980).

${ }^{25}$ Yerba Buena (Greenfield Center, New York: Greenfield Review Press, 1982) 8-9.

${ }^{26}$ Hay dos antologías de poesía que fueron esenciales para la circulación de la poesía nuyoriqueña y para su inclusión en el canon literario académico: Nuyorican Poetry, editado por Miguel Algarín y Miguel Piñero y Herejes y Mitificadores, editada por Efraín Barradas y Rafael Rodríguez.
} 
Short Eyes, de Miguel Piñero sitúa al público en una cárcel para que experimenten la vida de criminales y delincuentes. A la vez, Short Eyes revela la corrupción de la familia angloamericana ya que uno de los prisioneros, un hombre de familia, ha sido arrestado por el abuso sexual a niños. ${ }^{27}$ También, la cárcel no es un callejón sin salida sino un microcosmos de la estructura social anglo-americana, en la que se re-producen las mismas jerarquías de raza y comportamiento social. Aunque Short Eyes fue una producción comercial en Broadway, históricamente la obra confrontó al público anglo-americano con las realidades de la pobreza y de los marginales.

Por otro lado, fuera de Broadway, la comunidad puertorriqueña era testigo de un teatro que llevaba a escena los problemas del diario vivir, sus ansiedades y confrontaciones. A partir de los años sesenta, compañías de teatro como el Puerto Rican Ensemble, el Nuevo Teatro Pobre de América y el Teatro Rodante Puertorriqueño presentaron obras teatrales que reflejaban y refractaban la imagen y semejanza del latino, dando eco a sus testimonios de hibridez cultural, a sus confusiones y vacilaciones, y sobre todo instigando un orgullo cultural étnico de nación y de comunidad latina en los EE.UU..$^{28}$

Por ejemplo, en la década de los setenta, dos obras nos ubican en el corazón delghetto: Pipo Subway no sabe reir de Jaime Carreroy Simpson Street de Edward Gallardo. Ambas obras articulan la desesperación del pobre en situaciones de callejones sin salida, de mujeres abandonadas por los maridos, de hijosilegítimos, de la discriminación racial. Si en La carreta y en Encrucijada, las madres figuraron como entidades autoritarias y matriarcales, en estas obras de la década de los setenta las madres han perdido todo poder en la familia y sobre sus hijos. En Pipo Subway el hijo (niño) empuja por las escaleras a su madre preñada, ya que él no quiere un hermanito sino una bicicleta. ${ }^{29} \mathrm{En}$ Simpson Street

\footnotetext{
${ }^{27}$ Véase "Introduction" de Short Eyes en la que Marvin Félix Camillo explica cómo la obra fue el resultado de talleres llevados a cabo por "The Family", un grupo de presidiarios que evolucionaron a escritores y actores. Estos se consideraban a sí mismos una "familia teatral" de ex-convictos cuyo esfuerzo y dedicación llevó al éxito de Short Eyes.

${ }^{28}$ Para una historia del teatro latino en la Ciudad de Nueva York, véanse los siguientes artículos: VíctorFragoso, "Notas sobrela expresión teatral de la comunidad puertorriqueña de Nueva York", Revista del Instituto de Cultura Puertorriqueño 70 (enero-marzo, 1976) 21-26; John C. Miller, "Entrecruzamiento en el drama hispano contemporáneo de los Estados Unidos" en Imágenes e identidades, 299-306; Carlos Morton, "Nuyorican Theatre".The Drama Review 1 (marzo, 1976) 43-49; y Beatriz J. Risk, "El teatro hispano de Nueva York”, Centro de Documentacion Teatral, vol. 2 (Madrid: Forma, S.A., 1988) 307-323.

${ }_{29}$ Véase "Palabras y personajes" de Jaime Carrero para sus comentarios sobre Pipo Subway. Este artículo está incluido en Imágenes e identidades, 169-172. Carrero elabora lo siguiente sobre el personaje de Pipo y su forma de ser:

Y Pipo perdió la fe en el sistema de la familia. Lina, la amiga de Pipo, trató de consolarlo mencionanado el otro mundo de la calle Bedford en Brooklyn, donde un sueño de bicicletas de
} 
el hijo abandona a su madre y su familia y decide mudarse a California. En sus propias palabras él dice: "This is my own decision. It's something I've got to do for myself. There's nothing for me here. I just don't belong here anymore, $\mathrm{Ma}^{\text {" }}$ (89). Lucy, la madre, se siente abandonada y grita con histeria al final de la obra su deseo de partir también. Ella dice que es su derecho partir ya que ha cumplido con sus obligaciones familiares de madre y de padre:

I always thought about you Michael, think a little about me now. Don't be so selfish Michael. I gave up everything for you kids. Coño, it was hard trying to be both a mother and $a$ father to you after your father left, but I always did what I thought was best (91) One day it's gonna be me who leaves here. I swear it. One day you're gonna come to the door and not find me. It's time coño that I had a life of my own (93).

Con el modo de actuar del hijo de Lucy, se hace evidente que nuevos valores se han infiltrado en el hogar hispano. Estos son el individualismo, la competencia, la ambición, el egoísmo, y particularmente el consumismo. Es Pipo, el niño de Pipo Subway, quien da cuerpo a dicha actitud y deseo consumista, y quien fuerza a su madre a convertir las relaciones familiares en unas de consumo, según el modelo anglo-americano lo promueve conspicuamente en las campañas comerciales:

Ma', e' la veldá'. For once at least ... Por ahora ... For once ... Por primera ve' quiero algo nuevo. Algo que nadie tenga. Algo que sea mío pol primera vej. Quiero una bicicleta que nadie se sienta primero na'maj que yo... Yo, el primero. Nueva. Brand new. Pa' quitarle yo mi'mo loj papele' ... Y ponerle loj tolnillo' ... Y pegarle un sticker que diga ...: Brand new: Property of Pipo. En el asiento le pongo otro sticker que diga: Pipo, Superman (149).

La madre tiene que contestarle resignada: "Pipo ... Pipo, somoj pobre". Tal postura de Pipo demuestra cómo éste se ha apropiado e internalizadoel discurso capitalista patriarcal del sistema socio-político anglo-americano de poder. El niño debe eliminar, imponerse, silenciar y, si apareciera la ocasión, asesinar a la madre. Él también ya sabe que el modelo de la familia nuclear de clase media le ofrecería su deseada gratificación económica, por eso, al decir: "Muchos babies no function" (154), se hace evidente su anglo-americanización. Quisiera concluir este trabajo con una nota positiva refiriéndome a Migrants, una obra de teatro a la que asistí en octubre de 1987, presentada por Teatro Pregones. ${ }^{30}$

segundas manos podría convertirse en realidad. Pero Pipo estaba hastiado de las cosas de segundas manos. Todo el mundo quiere el sueño intacto, nuevecito, fresco, virgen. Y la pasion de Pipo no sabla lo que la palabra excepción significaba. Y hasta por ignorancia se hacen decisiones. Y Pipo hizo la suya (171-172).

30 Quiero expresar mi gratitud a los miembros de Teatro Pregones por enviarme información sobre la historia del grupo teatral, sus programas y sus talleres para la comunidad latina. 
Esta compañia se encarga de llevar a la comunidad latina obras que tratan de la problemática pertinente a su sobrevivencia cultural y a su identidad étnica. También la compañía ofrece talleres que son de vital importancia para el desarrollo socio-cultural de la comunidad latina. Migrants narra la historia del pueblopuertorriqueño, de un pueblocolonizado, oprimido, explotado y marginado a través de los siglos desde el descubrimiento, la conquista y colonización española hasta la invasión norteamericana de 1898. Pero esta historia de la Isla se descarrila hacia la historia de la inmigración de los puertorriqueños a la Isla de Manhattan. El drama se compone de una cornucopia de canciones y testimonios que narran la explotación y victimización de los inmigrantes. El programa declara tanto el propósito de la representación teatral como el de la praxis política de la compaña:

Why did they come here in the first place? We've been pushed and pulled ever since the United States took the Island in 1898. Some have stayed and given birth to a second and third generation; some have returned to the Island and others are still in never ending transit between here and there. With this collective creation, we weave through various social, historical, economical and personal factors that have influenced our migratory process. This is our homage to the courage and endurance of those who came and worked before us.

Migrants re-articula el relato/la historia de la inmigración de la familia y a la vez entreteje las vidas y trabajos de los inmigrantes desde sus comienzos. Aún más, la historia del pueblo oprimido se proyecta hacia un futuro como una comunidad bilingüe y bicultural en la que la "subjetividad" es/está en proceso constante. Los personajes saben que sus familias están en los EE.UU. para quedarse. El modo más fácil de escapar la opresión sería la vuelta definitiva a la Isla, pero un acto de valentía sería quedarse y luchar en los EE.UU. para lograr cambios sociales, respeto e igualdad. Sólo así el hogar hispano puede sobrevivir en la hostilidad y racismo del espacio anglo-americano, no solamente como una sola familia sino como una gran familia extendida. A pesar de que la familia hispánica ha sido desarticulada y desintegrada desde la inmigración inicial, en Migrants la familia sobrepasa la crisis haciendo de toda la comunidad latina -el ghetto- una gran familia que está políticamente consciente para su sobrevivencia, resistencia y continuación..$^{31}$

\footnotetext{
${ }^{31}$ Aquí quiero aclarar la distinción que he hecho entre los términos "hispano" y "latino". Uso "hispano" cuando las formaciones socio-culturales y la herencia cultural remiten a España (Hispania). Dado que "hispano" tiene una significación eurocéntrica que excluye a las poblaciones indias y africanas y a las culturas marginales de Latinoamérica, prefiero usar "latino" cuando me refiero a los pueblos de todas las razas de Latinoamérica que residen en los EE.UU.; incluyo tanto a los inmigrantes como a sus descendientes (Xavier F. Totti, 542). También "latino" tiene una significación política cuando el inmigrante latino de la clase proletaria define su identidad con el término. Por otro lado, generalmente, los que han recibido una educación universitaria y los inmigrantes elitistas que se
} 
identifican a priori con la cultura euro-española prefieren el término "hispano". Debe considerarse que el sistema político dominante anglo-americano impone la etiqueta de "hispanic" a todo individuo, según éstos, de descendencia hispana o que hable español. Actualmente, abogo por el término "latino" ya que es una palabra en español por lo que los anglo-americanos tienen que pronunciar una palabra en español. A la vez, con este término, se tienen que situar en relación con la clase proletaria latina en los EE. UU. y con Latinoamérica. Es crucial aclarar que en las universidades anglo-americanas cuando se dan cursos de literatura escrita por latinos, los académicos los etiquetan "literatura hispana”. ¿Es acaso éste un signo de elitismo y de euro-centrismo? Dichos académicos no permiten la inclusión de esta literatura en los departamentos de inglés aunque una gran parte está escrita en inglés. 
